\title{
Shock Wave Lithotripsy in Pediatric Stone Disease: A 15-Year Single-Center Experience with 2 Types of Lithotripters
}

\author{
Ariel Zisman Akram Assadi Oleg Goldin Kamil Malshy Omri Nativ \\ Shimon Meretyk Gilad E. Amiel Michael Mullerad Pinhas M. Livne \\ Urology Department, Rambam Health Care Campus, Haifa, Israel
}

\section{Keywords}

Shock wave lithotripsy · Pediatric stone disease $\cdot$ Urolithiasis
Conclusions: SWL in the pediatric population using the DLS showed good results with low complication rates that are equivalent to the gold standard HM3.

(C) 2022 The Author(s).

Published by S. Karger AG, Basel

\section{Introduction}

For several decades, SWL has become one of the main treatments for nephrolithiasis. According to several studies, pediatric stone-free rate (SFR) after SWL has been reported to be $60-90 \%$ [1-4]. The SFR depends on several factors such as stone location, stone composition, and stone length where stone size $\leq 12 \mathrm{~mm}$ is an independent predictor of SWL success [5]. Lower pole stone, calyceal stones, and stones impacted at the ureteropelvic junction have relatively poorer clearance and lower SFR [6].

The type of lithotripter machine is known to influence SFR in adults. The first-generation HM3 (Dornier MedTech Europe, Germany) is used as the reference lithotripter due to its higher SFR, fewer complications, and secondary treatments $[7,8]$. Nonetheless, comparative studies between HM3 and the newer generation lithotripters in pediatric population are sparse, and there is no
(C) 2022 The Author(s)

Published by S. Karger AG, Basel

This is an Open Access article licensed under the Creative Commons Attribution-NonCommercial-4.0 International License (CC BY-NC) (http://www.karger.com/Services/OpenAccessLicense), applicable to the online version of the article only. Usage and distribution for commercial purposes requires written permission.
Correspondence to:

Ariel Zisman, a_zisman@rmc.gov.il 
Table 1. Demographic features and stone-related parameters

\begin{tabular}{|c|c|c|c|}
\hline & $\begin{array}{l}\text { HM3 (group 1), } \\
n=41\end{array}$ & $\begin{array}{l}\text { DLS2 (group 2), } \\
n=66\end{array}$ & $\begin{array}{l}p \\
\text { value }\end{array}$ \\
\hline Age (mean), years & $10.83 \pm 5.39$ & $11.9 \pm 4.90$ & 0.27 \\
\hline Gender & $\begin{array}{l}27 \text { boys } \\
14 \text { girls }\end{array}$ & $\begin{array}{l}34 \text { boys } \\
32 \text { girls }\end{array}$ & 0.16 \\
\hline Stone size, $\mathrm{mm}$ & $11.58 \pm 5.32$ & $9.98 \pm 4.63$ & 0.08 \\
\hline Stone radiolucency & $\begin{array}{l}30 \text { radiopaque } \\
11 \text { radiolucent }\end{array}$ & $\begin{array}{l}47 \text { radiopaque } \\
19 \text { radiolucent }\end{array}$ & 1.00 \\
\hline Side (\%) & $\begin{array}{l}\text { Right (54) } \\
\text { Left (46) }\end{array}$ & $\begin{array}{l}\text { Right (54.5) } \\
\text { Left (45.5) }\end{array}$ & 1.00 \\
\hline $\begin{array}{l}\text { Metabolic disorder, } \% \\
\text { Stone location, } n(\%)\end{array}$ & 12 & 4.5 & 0.26 \\
\hline Upper calyx & $3(7.3)$ & $5(7.7)$ & 1.00 \\
\hline Middle calyx & $4(9.8)$ & $9(13.8)$ & 0.76 \\
\hline Lower calyx & $14(34.1)$ & $19(28.7)$ & 0.51 \\
\hline Renal pelvis & $10(24.4)$ & $23(35.4)$ & 0.28 \\
\hline Upper ureter & $4(9.8)$ & $3(4.6)$ & 0.43 \\
\hline Lower ureter & $6(14.6)$ & $7(10.8)$ & 0.55 \\
\hline
\end{tabular}

HM3, Dornier HM3; DLS, Dornier Lithotripter SII.
A comparative analysis was performed between the two groups for demographic features, stone parameters, SWL parameters, SFR, the need for auxiliary procedures, and complications. SFR was defined as a stone-free status or asymptomatic stone fragments smaller than $4 \mathrm{~mm}$ with no need of further treatment.

\section{SWL Treatment Plan}

Children on both groups of SWL machines were given general anesthesia during the procedure. Treatment session with the HM3 started at an intensity level of $6 \mathrm{kV}$ and gradually increased every 100 pulses until an intensity of $20 \mathrm{kV}$ for kidney stones and $26 \mathrm{kV}$ for ureteral stones. Treatment session with the DLS started at an intensity level of $2 \mathrm{~J}$ and gradually increased every 50 pulses by $1 \mathrm{~J}$ until an intensity of 6-7 J for kidney stones and 7-9 J for ureteral stones.

\section{Data Analysis}

Statistical analysis was done using the Fisher exact test to compare categorical parameters. A logistic regression model was conducted using multivariable categorical parameters in attempt to predict SWL SFR. The ROC model was performed. $p<0.05$ denoted statistical significance.

\section{Results}

Our cohort included 107 children who underwent SWL where HM3 was used in 38\% of children and DLS2 in $62 \%$ ( $n=41$ and 66, respectively). Average age was $11.5 \pm 5.1$ years (range 2-18). Most patients were boys. Average stone size was $10.6 \pm 4.9 \mathrm{~mm}$ (range $4-30$ ). The vast majority of stones were located in the kidney while the remaining in the ureter ( $81 \%$ vs. $19 \%$, respectively). There were no statistically significant variations between both groups regarding demographic features and stone-related parameters (Table 1). Seven children were previously stented and 10 carried a nephrostomy tube. As expected, radiopaque stones were more common than radiolucent ones ( $72 \%$ and $28 \%$, respectively). The mean HM3 stone size in millimeter was slightly larger than that in the DLS group, but this change did not reach statistical significance (11.58 vs. 9.9, $p=0.08$ ). The mean number of shock waves per session was comparable between both groups: 2,604 in the HM3 group and 2,695 in the DLS group $(p=0.22)$. Seven children underwent pre-SWL kidney drainage in the HM3 group compared to 10 children in the DLS group (NS).

When comparing the total SFR, there was no statistically significant difference among both groups: HM3 $(83 \%)$ or DLS $(74 \%)(p=0.35)$. SFR after one SWL session showed better results in the HM3 (78\% vs. $62 \%, p=0.093$ ). Re-treatment rates were $22 \%$ and $17 \%$ in the HM3 and DLS2 groups $(p=0.61)$. The complication rate was relatively low in both groups where renal colic was the most common one (HM3 10\%, DLS 20\%, NS). Steinstrasse re- 
Table 2. Comparison of treatment-related parameters, SFR, and complications

\begin{tabular}{llll}
\hline & HM3 (group 1), DLS2 (group 2), & $p$ \\
$n=41$ & & \\
& $n=66$ & \\
& & & \\
\hline $\begin{array}{l}\text { Pre-SWL kidney drainage } \\
\quad \text { DPT stent }\end{array}$ & 1 & 6 & 0.25 \\
$\quad$ Nephrostomy tube & 6 & 4 & 0.17 \\
$\begin{array}{l}\text { Shock waves, } n \\
\text { SFR, } n \text { (\%) }\end{array}$ & $2,604 \pm 437$ & $2,695 \pm 320$ & 0.22 \\
$\quad$ & & & \\
$\quad$ SFR after 1 SWL & $32(78)$ & $41(62)$ & 0.093 \\
$\quad$ Overall SFR & $34(83)$ & $49(74)$ & 0.35 \\
$\begin{array}{l}\text { Re-treatment rate, \% } \\
\text { Complication, } n \text { (\%) }\end{array}$ & 22 & 17 & 0.61 \\
$\quad$ Renal colic & 10 & 20 & \\
$\quad$ Fever & 4.9 & 4.5 & 0.28 \\
$\quad$ Hematoma & 0 & 1.5 & 1.00 \\
$\quad$ Steinstrasse & 4 & 2 & NS \\
\hline
\end{tabular}

HM3, Dornier HM3; DLS, Dornier Lithotripter SII; SFR, stone-free rate; $S W L$, shock wave lithotripsy; DPT, double pig tail.

quiring ureteral stenting or ureteroscopy was noted in 2 children after SWL with the HM3 and in 1 child with the DLS (NS, Table 2).

When analyzing the entire cohort by using a logistic regression model, the location of the stone was found to be a predictor of SFR. Kidney stones had better SFR compared with ureteral stones $(p=0.019$, OR $3.61,95 \%$ CI: $1.2-10.5)$. In addition, stones smaller than $12.5 \mathrm{~mm}$ had a greater SFR, however with borderline clinical significance ( $p=0.092$, OR 2.3, 95\% CI: 0.8-6.1).

\section{Discussion}

The main goal of SWL in children is achieving a stonefree status with minimal re-treatment rates and post-procedure complications. Physiologic factors that are believed to increase pediatric SFR over adults are softer stone composition, relatively smaller stone size, increased ureteral compliance to accommodate residual fragments that gives a better transport ability, and smaller body mass to facilitate SWL transmission $[9,10]$.

In our study, we observed a total SFR of $78 \%$ which aligns with the reported SFR in the literature, ranging from $60 \%$ to $90 \%$ [2, 6, 11-13]. We compared two different technologies of ESWL:

1. The electrohydraulic lithotripter where an intrinsic source generates a shock wave that is focused by using an ellipsoidal reflector. The pressure pulse originates as a shock wave and remains a shock wave at all times. Since it is a wave, during emission, there can be significant variation in the amplitude of the shock, and there can be some shift in the position of the focal point at the target.

2. The electromagnetic lithotripter uses as an acoustic source an electrical coil in proximity to a metal plate. When the coil is excited by a short electrical pulse, an acoustic wave is generated. Focusing is very accurate, and the variation in measured pressure waves is less than $10 \%[14,15]$.

The shock wave generated using the oldest lithotripter, the electrohydraulic HM3, was believed to produce the best stone disintegration in the adult population. The Dornier lithotripter S II system, which utilizes an electromagnetic shockwave generator, has a much smaller focal area and may be less powerful. For these reasons, patient positioning and stone localization must be exact with the DLS. This might explain why SFR in adults is reported to be lower with electromagnetic lithotripters than with the broad focal area of the electrohydraulic HM3 $[7,8]$.

Few studies have focused on the question whether the type of lithotripter machine influences SFR in children. Raza et al. [16] reported an SFR of 95\% using an electrohydraulic lithotripter versus $77 \%$ for an electromagnetic lithotripter, similar to what was reported in the adult population. Another comparative study conducted by Elsobky et al. [17] concluded that the re-treatment rate differed significantly between the electrohydraulic and piezoelectric lithotripters, but the SFR did not. To our knowledge, no other direct comparison between electrohydraulic and electromagnetic lithotripters was done in pediatric patients. In our pediatric cohort, SFR after one SWL using the electrohydraulic HM3 was better than the electromagnetic DLS, with borderline clinical significance (78\% vs. $62 \%, p=0.093)$. Nonetheless, a comparison of the total SFR between the two groups did not reach a statistical significant difference ( $83 \%$ vs. $74 \%, p=0.35$, Table 2 ). Our study did not find differences in re-treatment rates, with approximately $20 \%$ re-treatments in both groups.

SWL is generally well tolerated by children with complication rates not exceeding $20 \%$ in most series $[18,19]$. The most common complication after SWL in our series was transient flank pain (HM3 10\%, DLS 20\%, NS, Table 2). Steinstrasse, a common condition following SWL, was noted in less than $5 \%$ in each group of our cohort.

A systematic review and meta-analysis that examined the clinical efficacy of SWL in pediatric urolithiasis found that SFR for stones less than $10 \mathrm{~mm}$ was significantly 
higher than that for stones greater than $10 \mathrm{~mm}$ in children [20]. Similar results were seen in our cohort, where a stone size smaller than $12.5 \mathrm{~mm}$ predicted a greater SFR with a borderline significance $(p=0.092)$.

The alternatives to SWL are PCNL and ureteroscopy. Both treatment options have been used in the adult population for many years. Rapid advances in technology with development of smaller and more flexible endoscopes as well as tubeless PCNL have now made it possible to apply them for the treatment of pediatric stone disease. These advances bring stone clearance for both URS and PCNL to an overall SFR of $95-100 \%$ with minimal complications $[21,22]$. Although single-session SFRs of both RIRS and PCNL are significantly higher than SWL, compared with these invasive procedures, pediatric SWL still offers the advantages of a noninvasive procedure, shorter operative time with minimal anesthesia, shorter hospitalization, and a cost-effective procedure [21,23-26].

When comparing our cohort results with reports from the adult population, SWL using the newer generation electromagnetic lithotripters can be as effective as the older generation electrohydraulic lithotripters with acceptable re-treatment and complications rates. The smaller focal area of the electromagnetic lithotripters compared to electrohydraulic lithotripters might make stone disintegration in children optimal. This might be explained by the shorter skin-to-stone distance in the pediatric population, compared to adults.

Our study has several limitations:

- It was a retrospective study with a relatively small patient population; the DLS system was not applied after 2016 due to nonmedical reasons. Future studies with a larger sample size would improve the results.

- We did not exclude children with a history of urological surgery such as ureteroscopy and PCNL, which might decrease SFR. Children with a history of urological surgery or anatomical abnormalities were found to have lower SFR after SWL when compared to children without these conditions [12]. A retrospective research of 64 patients achieved $90 \%$ SFR after excluding these patients [4].

- The majority of our pediatric cohort (90\%) were diagnosed by abdominal X-ray and/or ultrasound and not by NCCT because of the potential risks of ionizing radiation [27]. Therefore, we were unable to collect sufficient data concerning the density of the stones in Hounsfield Units (HU). The HU of a stone measured in NCCT has been shown to be a predictive factor for SWL success in children. Stones with lower HU $(<1,000)$ were correlated with better SFR [28].

\section{Conclusions}

SWL in pediatric patients is a noninvasive and effective treatment for renal and ureteral stones. The DLS lithotripter showed comparable efficacy and complication rates to the gold standard HM3. SWL should be offered as one of the primary treatment options in pediatric stone disease.

\section{Statement of Ethics}

The research complies with the guidelines for human studies and was conducted ethically in accordance with the World Medical Association Declaration of Helsinki. The study protocol was reviewed and approved by the Rambam Medical Center (Affiliated with the Technion - Israel Institute of Technology) Helsinki Committee on Human Research. Approval No. IRB \#0254-16. Consent from patients was not obtained because this was a retrospective chart review study that does not affect clinical care of the individuals. This was approved by the ethics committee.

\section{Conflict of Interest Statement}

The authors have no conflicts of interest to declare.

\section{Funding Sources}

The authors have no funding sources to report.

\section{Author Contributions}

Ariel Zisman conceived and designed the analysis, collected the data, performed the analysis, and wrote the paper. Akram Assadi conceived and designed the analysis, performed the analysis, and wrote the paper. Oleg Goldin contributed data and designed the analysis. Kamil Malshy collected the data and designed the analysis. Omri Nativ collected the data and designed the analysis. Shimon Meretyk contributed data and designed the analysis. Gilad E. Amiel conceived and designed the analysis. Michael Mullerad conceived and designed the analysis, performed the analysis, and wrote the paper. Pinhas M. Livne conceived and designed the analysis, performed the analysis, and wrote the paper.

\section{Data Availability Statement}

Due to the possibility of compromising the privacy of research participants, the data supporting this study are not publicly available. However, they can be obtained from the corresponding author A.Z. at a_zisman@rmc.gov.il upon reasonable request. 


\section{References}

1 Kurien A, Symons S, Manohar T, Desai M. Extracorporeal shock wave lithotripsy in children: equivalent clearance rates to adults is achieved with fewer and lower energy shock waves. BJU Int. 2009 Jan;103(1):81-4.

2 Soygur T, Arikan N, Kilic O, Suer E. Extracorporeal shock wave lithotripsy in children: evaluation of the results considering the need for auxiliary procedures. J Pediatr Urol. 2006 Oct;2(5):459-63. Available from:

3 Landau EH, Shenfeld OZ, Pode D, Shapiro A, Meretyk S, Katz G, et al. Extracorporeal shock wave lithotripsy in prepubertal children: 22year experience at a single institution with a single lithotriptor. J Urol. 2009 Oct;182(4 Suppl):1835-40. Available from:

4 Jeong US, Lee S, Kang J, Han DH, Park KH, Baek M. Factors affecting the outcome of extracorporeal shock wave lithotripsy for unilateral urinary stones in children: a 17-year single-institute experience. Korean J Urol. 2013;54(7):460.

5 El-Assmy A, El-Nahas AR, Abou-El-Ghar ME, Awad BA, Sheir KZ. Kidney stone size and Hounsfield units predict successful shockwave lithotripsy in children. Urology. 2013 Apr;81(4):880-4.

6 Ather MH, Noor MA. Does size and site matter for renal stones up to $30-\mathrm{mm}$ in size in children treated by extracorporeal lithotripsy? Urology. 2003 Jan;61(1):212-5.

7 Gerber R, Studer UE, Danuser H. Is newer always better? A comparative study of 3 lithotriptor generations. J Urol. 2005 Jun;173(6): 2013-6.

8 Zehnder P, Roth B, Birkhäuser F, Schneider S, Schmutz R, Thalmann GN, et al. A prospective randomised trial comparing the modified HM3 with the MODULITH ${ }^{\oplus}$ SLX-F2 lithotripter. Eur Urol. 2011 Apr;59(4):637-44. Available from: https://linkinghub.elsevier. com/retrieve/pii/S0302283811000479.

9 Gofrit ON, Pode D, Meretyk S, Katz G, Shapiro A, Golijanin D, et al. Is the pediatric ureter as efficient as the adult ureter in transporting fragments following extracorporeal shock wave lithotripsy for renal calculi larger than 10 mm? J Urol. 2001 Nov;166(5):1862-4.
10 Garg G, Aggarwal A, Singh M, Sankhwar SN, Sharma D, Pandey S. Comparison of efficacy and safety of ESWL in paediatric and adolescent versus adult urolithiasis: a single center 5 -year experience from a tertiary care hospital. Afr J Urol. 2018 Dec;24(4):315-8.

11 Rodrigues Netto N, Longo JA, Ikonomidis JA, Rodrigues Netto MC. Extracorporeal shock wave lithotripsy in children. J Urol. 2002 May; 167(5):2164-6.

12 Nelson CP, Diamond DA, Cendron M, Peters CA, Cilento BG. Extracorporeal shock wave lithotripsy in pediatric patients using a late generation portable lithotriptor: experience at Children's Hospital Boston. J Urol. 2008; 180(4 Suppl L):1865-8.

13 McAdams S, Kim N, Dajusta D, Monga M, Ravish IR, Nerli R, et al. Preoperative stone attenuation value predicts success after shock wave lithotripsy in children. J Urol. 2010 Oct; 184(4S):1804-9.

14 Bianchi G, Marega D, Knez R, Bucci S, Trombetta C. Comparison of an electromagnetic and an electrohydraulic lithotripter: efficacy, pain and complications. Arch Ital Urol Androl. 2018 Sep 30;90(3):169-71.

15 Mustafa M, Aburas H, Helo FM, Qarawi L. Electromagnetic and electrohydraulic shock wave lithotripsy-induced urothelial damage: is there a difference? J Endourol. 2017 Feb; 31(2):180-4.

16 Raza SJ, Ather MH. Does the type of lithotripter affect outcomes in children with upper tract urolithiasis? J Endourol. 2009 Feb;23(2): 223-7.

17 Elsobky E, Sheir KZ, Madbouly K, Mokhtar AA. Extracorporeal shock wave lithotripsy in children: experience using two second-generation lithotripters. BJU Int. 2001 Dec 24; 86(7):851-6.

18 Zeng G, Jia J, Zhao Z, Wu W, Zhao Z, Zhong W. Treatment of renal stones in infants: comparing extracorporeal shock wave lithotripsy and mini-percutaneous nephrolithotomy. Urol Res. 2012 Oct 13;40(5):599-603.

19 Grivas N, Thomas K, Drake T, Donaldson J, Neisius A, Petřík A, et al. Imaging modalities and treatment of paediatric upper tract urolithiasis: a systematic review and update on behalf of the EAU urolithiasis guidelines panel. J Pediatr Urol. 2020 Jul. Available from: https: //linkinghub.elsevier.com/retrieve/pii/ S1477513120304137.
20 Lu P, Wang Z, Song R, Wang X, Qi K, Dai Q, et al. The clinical efficacy of extracorporeal shock wave lithotripsy in pediatric urolithiasis: a systematic review and meta-analysis. Urolithiasis. 2015 Jun 27;43(3):199-206.

21 Chan LH, Good DW, Laing K, Phipps S, Thomas BG, Keanie JY, et al. Primary SWL is an efficient and cost-effective treatment for lower pole renal stones between 10 and 20 $\mathrm{mm}$ in size: a large single center study. J Endourol. 2017 May;31(5):510-6.

22 Salem HK, Morsi HA, Omran A, Daw MA. Tubeless percutaneous nephrolithotomy in children. J Pediatr Urol. 2007 Jun;3(3):235-8. Available from: https://linkinghub.elsevier. com/retrieve/pii/S1477513106001318.

23 Constanti M, Calvert RC, Thomas K, Dickinson A, Carlisle S. Cost analysis of ureteroscopy (URS) vs. extracorporeal shockwave lithotripsy (ESWL) in the management of ureteric stones $<10 \mathrm{~mm}$ in adults: a UK perspective. BJU Int. 2020 Mar 30;125(3):45766.

24 He Q, Xiao K, Chen Y, Liao B, Li H, Wang K. Which is the best treatment of pediatric upper urinary tract stones among extracorporeal shockwave lithotripsy, percutaneous nephrolithotomy and retrograde intrarenal surgery: a systematic review. BMC Urol. 2019 Dec 23; 19(1):98.

25 Esposito C, Masieri L, Bagnara V, Tokar B, Golebiewski A, Escolino M. Ureteroscopic lithotripsy for ureteral stones in children using holmium: yag laser energy - results of a multicentric survey. J Pediatr Urol. 2019 Aug; 15(4):391.e1-e7.

26 Safwat AS, Bissada NK, Kumar U, Taha MI, Abdel-hafez SES, Eltaher AM, et al. Experience with ureteroscopic holmium laser lithotripsy in children. Pediatr Surg Int. 2008 May 26;24(5):579-81. Available from: http://link. springer.com/10.1007/s00383-008-2119-7.

27 Gupta A, Castellan M. Use of computed tomography $(\mathrm{CT})$ for urolithiasis in pediatric patients. Transl Pediatr. 2015;4(1):33-5.

28 Perks AE, Gotto G, Teichman JM. Shock wave lithotripsy correlates with stone density on preoperative computerized tomography. J Urol. 2007 Sep;178(3 Pt 1):912-5. 